\title{
INFO FROM THE WORLD
}

\section{POWER DYNAMICS AND CONFLICT OF INTER- ESTS IN THE WASTE SECTOR: THE CASE OF NAIROBI, KENYA}

Waste management raises concerns on environmental degradation and public health issues in the city of Nairobi, Kenya where a big share of the urban population still suffers from lack of adequate waste collection services. Governmental and international efforts have focused on implementing waste operations in middle- and high-income areas that fall short of providing informal settlements with equally efficient facilities (Figure 1). This results in increased rates of urban inequalities as well as places waste issues in the broader framework of environmental injustice and marginalization of the poor.

In response to the current gaps, the emergence of spontaneous, informal clean-up activities sheds light on the willingness of communities to be more involved in waste management activities. To that extent, consideration should be given to environmental education and awareness programs to provide the general public with skills and training in the waste sector. It is also important to include them in decision-making processes by supporting participatory planning and co-design of innovative waste management strategies.

There are multiple causes preventing the conduction of efficient Solid Waste Management (SWM) services. Among those, spatial and management concerns are raising about the increasing number of unauthorized dumping sites as opposed to the Dandora Municipal Dumping Site which has been declared "full" for years and keeps on receiving waste material to be disposed of (Kimani 2007).

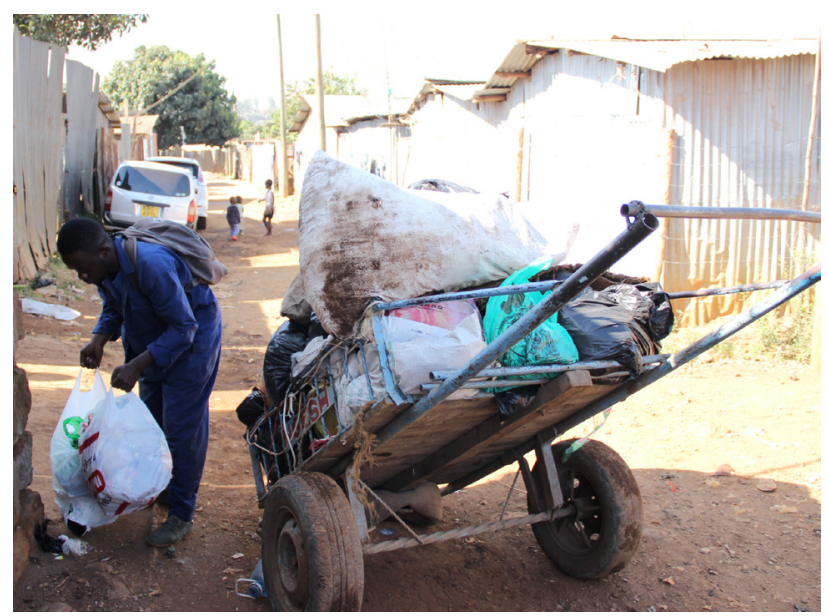

FIGURE 1: Waste collection in informal areas and slums by CBOs. Credits by the author (2016).
Not only does lack of spatial control exacerbate potential risks to human health and the environment, but it also triggers conflicts of interest among the various stakeholders driving illegal businesses and waste trafficking (Njoroge et al., 2014). Illegal waste activities refer to any waste movement that lays outside the regulatory framework Tompson and Chainey, 2011). Both increased levels of urban poverty and lack of regular income foster scavenging operations to sell recovered materials.

Currently, the collection rate is 33 percent, which means that 2,690 tons of waste material (Figure 2) remains uncollected every day. About 100 to 150 tons of waste are reused and recycled daily, equivalent to 3.7 percent of the total waste generated. Those services account for waste fees paid directly to the City Council of Nairobi (CCN) where residents are charged on the basis of the service supplied. However, municipal collection services only cover medium- and high-income areas while cutting out low-income areas and slums which are where more than a half of Nairobi's population lives (Njoroge et al., 2014).

\section{RECOMMENDATIONS}

Easy access to SWM. Waste services should be extended to a broader share of Nairobi's population by supplying households in both high-income and slum areas and reducing the fees for the municipal service. Collection activities should be scheduled on a weekly basis and be coupled with regular clean-up of streets and public spaces as well as monitoring of collection and disposal areas.

Nudge interventions. These interventions address the installation of collection sites in open and common spaces where people can deliver garbage. Collection points will be easily recognizable and associated with informational signs. They will also host workshop activities to educate local communities on the importance of recovery and recycling.

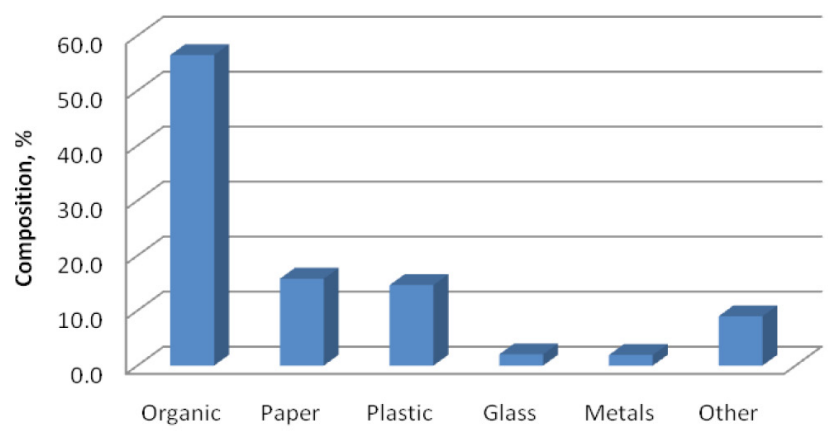

FIGURE 2: Physical composition of MSW in Nairobi (Njoroge et al., 2014). 
Incentive-based system. This will provide financial rewards for those who segregate materials and bring garbage to collection areas by attaching monetary values to waste resources and giving new life to recovered materials. With hopes of promoting pro-environmental and more responsible behaviors, we aim to change injunctive norms by promoting good waste practices.

Hybrid governance in the waste sector. There is a need to coordinate public and private efforts in the waste sector in order to avoid conflict among resources and illegal competition for inadequate and insufficient service provision. To that end, we advocate better management of the power structures playing in the waste sector by supporting collaboration and shared responsibilities among $\mathrm{CCN}$, local and international NGOs, private companies, and local communities.

Public awareness and informational interventions. Beyond action, awareness on waste pollution as a major cause of environmental degradation and disease outbreak is needed. Education on the ease of recycling also plays a crucial role. This can be achieved by installing containers for recyclables, informational signs on trashcan use, how to recognize different materials, facts about the downsides of illegally disposed waste, and examples of successful cases in similar contexts.
Participatory planning and co-design. Local communities should be more empowered in the environmental clean-up process by co-designing strategies and taking part in decision-making along with municipal actors and private waste companies. This would allow for the creation of a more responsible, cleaner and environmentally-friendly system where roles and benefits are equally shared among Nairobi's population thereby promoting procedural justice.

Carol Maione ${ }^{1, *}$ and Negar Aliakbarshirazi ${ }^{2}$

${ }^{1}$ School for Environment and Sustainability, University of

Michigan, Arbor, USA

${ }^{2}$ Department of Architecture and Urban Studies, Politecnico di Milano, Italy

* email: cmaione@umich.edu

\section{REFERENCES}

Kimani, N. (2007). Environmental Pollution and Impact to Public Health; Implication of the Dandora Municipal Dumping Site in Nairobi, Kenya. Nairobi: UNEP.

Njoroge, B.N.K, Kimani, M., and Ndunge, D. (2014). Review of Municipal Solid Waste Management: A Case Study of Nairobi, Kenya. International Journal of Engineering and Science, 4(2): 16-20.

Tompson, L., and Chainey, S. (2011). Profiling Illegal Waste Activity: Using Crime Scripts as a Data Collection and Analytical Strategy. European Journal on Criminal Policy and Research, (2011)17: 179-201. 